\title{
Effects of Weather and Climatic Elements on the Incidence of Pneumonia in Kaduna South Local Government Area, North Western Nigeria
}

\author{
Felix Ike*, Chioma Mbonu \\ Department of Geography and Planning, Faculty of Environmental Science, Abia State University, Uturu, Nigeria \\ Email address: \\ chiemzy@yahoo.com (F. Ike),mbonuchioma09@gmail.com (C. Mbonu) \\ *Corresponding author \\ To cite this article: \\ Felix Ike, Chioma Mbonu. Effects of Weather and Climatic Elements on the Incidence of Pneumonia in Kaduna South Local Government \\ Area, North Western Nigeria. Earth Sciences. Vol. 8, No. 3, 2019, pp. 126-131. doi: 10.11648/j.earth.20190803.11
}

Received: March 17,2019; Accepted: April 23, 2019; Published: May 29, 2019

\begin{abstract}
This study assessed the relationship between weather and climatic elements on the incidence of pneumonia in Kaduna South Local Government Area, North Western Nigeria. The main objective of the study was to determine the incidences of pneumonia and assess its relationship with weather elements. This paper also reported on the seasonality of Weather parameters and how they can affect pneumonia occurrence in the study area. The data used were meteorological (Rainfall, Humidity and Temperature) and pneumonia records collected from Nigerian Meteorological Agency and Government General Hospital, Kakuri respectively. Multiple regression model and seasonality metrices were employed in the analysis of the data to determine the strength of relationship between the weather parameters and the frequency of pneumonia outbreak. The model run indicated that the combined effect of temperature, rainfall and humidity significantly accounts for variations in Pneumonia occurrence at different level of probability. However the weather elements could only explain $16 \%$ of the variations in the incidence of Pneumonia in the study area for the period between 2008 and 2015. The examination of the seasonal occurrence revealed that pneumonia occurred mostly in the cold \& wet season and the cold \& dry seasons. The study concluded that weather elements play a role in the incidence of pneumonia in the study area and should be considered along with other factors in mitigating its occurrence.
\end{abstract}

Keywords: Seasonality, Pneumonia, Trends, Rainfall, Humidity and Temperature

\section{Introduction}

It is generally acknowledged that our climate is changing and these changes have the potential to affect human health [1]. The population of all organisms depends upon the supplies of food and water, freedom from excess infectious diseases and the physical safety and comfort conferred by climatic stability. The characteristics, geographical distribution and seasonal variations of most infectious diseases are evidence that their occurrences could be linked to weather and climate factors. Extremes of temperature, precipitation and humidity affect the life cycle of many disease pathogens and vectors (both directly and indirectly) and this potentially affects the timing and intensity of disease outbreak [2]. More acutely, disaster and disease outbreaks have occurred very often in response to extreme regional climate cycles such as El Nino/ Southern oscillations (ENSO) cycles [3]. Climate can affect human health directly through the impact of thermal stress, death and injury in flood and storms and indirectly through changes in ranges of disease vectors, water-borne pathogens and air borne pathogens. Climatic factors are important determinants of various respiratory diseases. Relationship between year to year variations in climate and respiratory diseases are more evident where climatic variations are marked with vulnerable populations $[3,4]$

Pneumonia accounts for more under -fives mortality than malaria, AIDS and meningitis combined [5]. A recent community-based survey indicated that $20 \%$ of Kaduna children die before their 5th birthday and pneumonia alone accounts for $16 \%$ of under-five mortality [6]. Weather elements affect the timing and intensity of the outbreak of 
respiratory diseases (pneumonia) which the people are ignorant of and this seems to be the reason for ill health, increased hospitalization and death rate in the locality which the forgoing literatures have not addressed.

The physiological function of the human body responds to changes in weather condition. Indeed the seasonal or periodic nature of outbreaks of some human diseases such as respiratory diseases suggests that climate conditions play an important role in the seasonal variations [7]. Most vectorborne diseases exhibit a seasonal pattern [8] which clearly suggests that they are weather sensitive. Rainfall, temperature, relative humidity, wind, cloud and sunshine affect in many ways both the vectors and pathogens they transmit spatially and temporarily. They may have a profound impact on transmission cycles of diseases by influencing the availability of vector longevity and altering host breeding and migration pattern. For example, high temperatures can increase or reduce survival rate, depending on the vector, its behaviour and many other factors $[6,8]$. Thus the probability of transmission may or may not be increased by higher temperatures.

Ojo, O, [9] reported that weather parameters influence the incidences of diseases in two major ways. Firstly, they affect the resistance of the human body making it more susceptible to diseases. Secondly, weather parameters influence growth, propagation and spread of some diseases like pneumonia, malaria and meningitis. Tania A. et al. [10], reported that exposures to carbon monoxide and nitrogen oxide can cause aggravation of existing cardiovascular diseases, affect breathing, respiratory illness, lung irritation and alterations in the lungs defence system.

It has been observed that in Nigeria, very little effort have been made to identify the effects of weather conditions on the occurrence of respiratory diseases. It is pertinent therefore, that a study of this nature be carried out so as to provide background information for health care practitioners on effects of weather and climatic elements on pneumonia.

\section{Methodology}

\subsection{The Study Area}

Kaduna south local government area is one of the 23 L.G.As of Kaduna state. It is surrounded by Kaduna North L.G.A to the North, Igabi L.G.A to the West and Chikun L.G.A to the South and East. It is located approximately between latitude $9^{\circ} 54^{\prime} \mathrm{N}$ and $10^{\circ} 29^{\prime} \mathrm{N}$ and between longitude $6^{\circ} 59^{\prime} \mathrm{E}$ and $8^{\circ} 09^{\prime} \mathrm{E}$ (Figure 1).

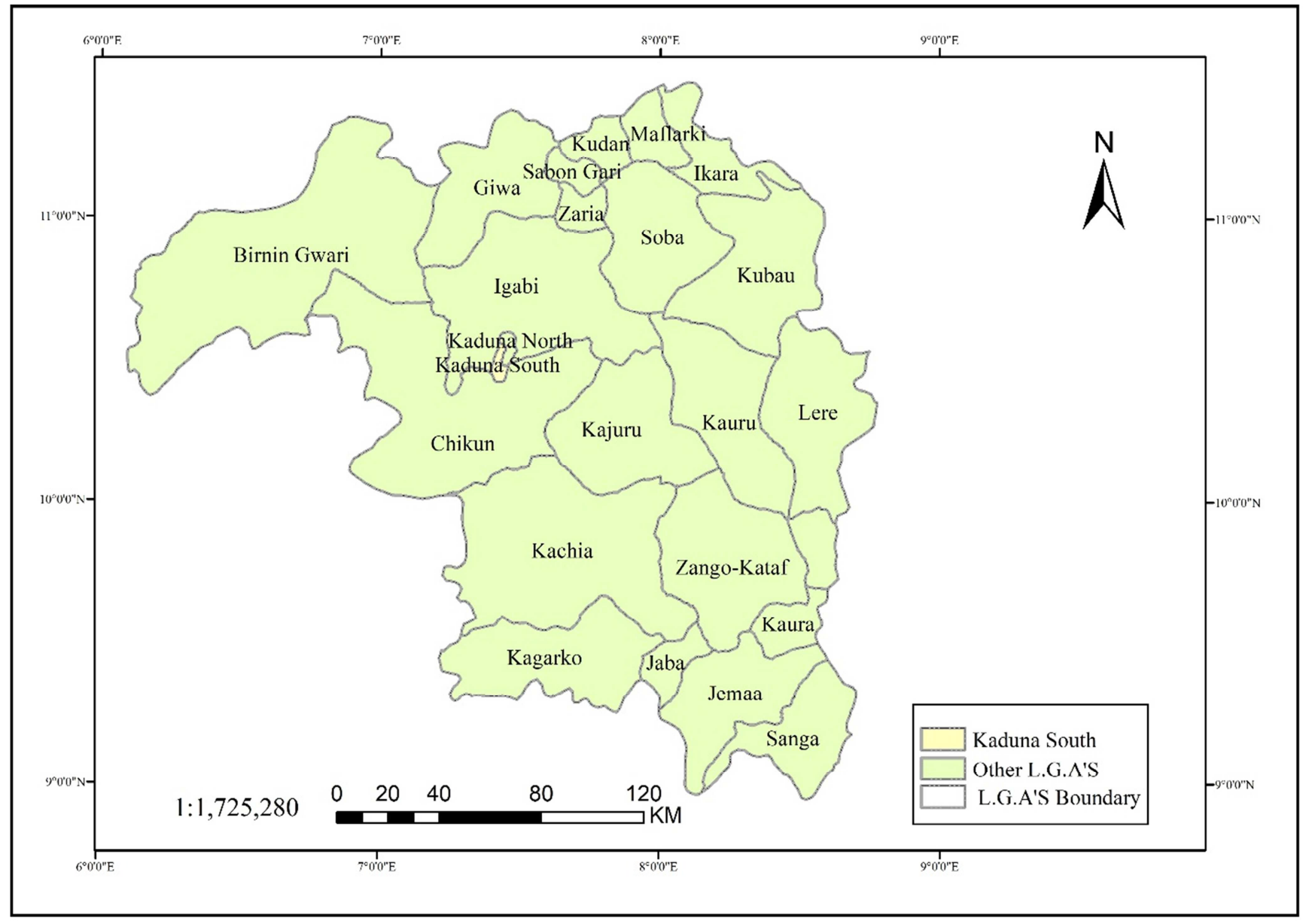

Figure 1. Kaduna State, Showing the Study Area. 
The climate of Kaduna metropolis is influenced by two dominant air masses namely; the tropical maritime or southwest trade wind which blows across the Atlantic Ocean and the tropical continental or north-east trade wind which blows across the Sahara desert. The rainy season lasts from AprilOctober (about 7 months) with its peak in July to August. The average annual rainfall is about $1000-1400 \mathrm{~mm}$. Temperatures are high throughout the year with the highest in March (about $38.6^{\circ} \mathrm{C}$ ). The lowest is in January (about $20.2^{\circ} \mathrm{C}$ ). Relative humidity in the dry season is below $10 \%$ in the afternoon and $90 \%$ at dawn. During the rainy season, the relative humidity can be over $70 \%$ in the midday and $95 \%$ at dawn [11]

The vegetation of the area with an annual rainfall of about $1000-1400 \mathrm{~mm}$ is typical Guinea savannah with tall grasses of about $1.5-2 \mathrm{~m}$ in height, scattered trees and gallery forest along river courses.

\subsection{Data and Analysis}

The data collection exercise involved collection of numerical meteorological and hospital data. Purposive sampling technique was used in the collection of hospital data from Government General Hospital Kaduna. The choice of this hospital was based on the fact that the above named hospital has existed for over 8 years and has the records of permanent residents in the study area treated between 2008 and 2015. The choice was also based on the fact that all pneumonia cases that are reported to all the Primary Health Care centers in the local government are referred to the
General Hospital based on government directives.

The meteorological data of the study area was collected from NIMET (Nigerian meteorological Agencyhttps://nimet.gov.ng/) Kaduna state chapter. The data collected were for temperature, rainfall and relative humidity covering the period between 2008 and 2015. The medical record on the incidence of Pneumonia covering 2008 to 2015 were also collected from Government General Hospital, Kaduna. To determine the relationship between the weather elements (temperature, relative humidity and rainfall) and the incidence of pneumonia in Kaduna South Local Government area, the ordinary least square (OLS) estimates of the multiple regression models was used. To harmonize the data sets for relationship determination, values of climatic elements and reported cases of the disease were also transformed to a common base using $\log 10$ [12]. The multiple correlation coefficient formula is given by

$$
Y i=B 0+\beta 1 X 1 i+\beta 2 X 2 i+\beta 3 X 3 i+\varepsilon i
$$

Where: $\mathrm{Yi}$ is the dependent value or incidence of Pneumonia and $\mathrm{B} 0$ is the constant showing intercept for regression, $\mathrm{X} 1 \mathrm{i}, \mathrm{X} 2 \mathrm{i}$, and $\mathrm{X} 3 \mathrm{i}$ represents the temperature, rainfall and relative humidity respectively. $\beta 1$ to $\beta 3$ are the independent variable coefficients while ci represents the error term. The seasonal metrices of the occurrences were determined by aggregating the pneumonia counts into for seasonal threshold of Cold/ dry, Hot / dry Warm/ Wet, Cold /Wet and Cold / dry.

\section{Results}

\subsection{Trends in Weather Parameters and Incidence of Pneumonia}

Table 1. Temperature metrices $\left({ }^{\circ} \mathrm{C}\right)$ from 2008-2015 in the study area.

\begin{tabular}{|c|c|c|c|c|c|c|c|c|c|}
\hline & 2008 & 2009 & 2010 & 2011 & 2012 & 2013 & 2014 & 2015 & MONTHLY MEAN \\
\hline JAN & 22.2 & 24.7 & 24.0 & 22.9 & 23.0 & 24.7 & 24.7 & 22.6 & 23.6 \\
\hline FEB & 24.7 & 27.1 & 27.6 & 27.5 & 27.3 & 26.9 & 26.7 & 27.7 & 26.9 \\
\hline MAR & 29.3 & 29.3 & 29.4 & 28.9 & 28.2 & 29.6 & 29.2 & 28.8 & 29.1 \\
\hline APR & 29.2 & 29.4 & 29.8 & 29.4 & 29.3 & 29.0 & 29.3 & 29.3 & 29.3 \\
\hline MAY & 26.9 & 28.0 & 28.3 & 27.5 & 26.9 & 27.6 & 27.4 & 29.2 & 27.7 \\
\hline JUN & 26.2 & 25.7 & 26.2 & 26.1 & 25.5 & 25.6 & 30.0 & 26.4 & 26.5 \\
\hline JUL & 24.6 & 24.9 & 24.9 & 25.1 & 24.5 & 24.6 & 25.3 & 25.4 & 24.9 \\
\hline SEP & 25.5 & 25.6 & 24.7 & 25.4 & 24.9 & 25.1 & 25.0 & 25.2 & 25.2 \\
\hline OCT & 25.1 & 25.9 & 26.3 & 25.8 & 26.4 & 25.7 & 25.6 & 26.7 & 25.9 \\
\hline NOV & 24.5 & 24.4 & 25.4 & 23.8 & 25.4 & 25.5 & 25.4 & 24.8 & 24.4 \\
\hline DEC & 24.3 & 23.5 & 23.0 & 22.7 & 23.8 & 24.1 & 23.7 & 21.5 & 23.3 \\
\hline ANNUAL MEAN & 25.6 & 26.1 & 26.2 & 25.8 & 25.8 & 26.0 & 26.4 & 26.1 & \\
\hline
\end{tabular}

As indicated in Table 1, maximum annual mean temperature of $26.4^{\circ} \mathrm{C}$ was recorded in 2014 . Generally, for the period between 2008 and 2015, the months of March to June accounted for the maximum temperature readings. Correspondingly, the maximum and minimum monthly mean temperature were recorded in April $\left(29.3^{\circ} \mathrm{C}\right)$ and December $\left(23.3^{\circ} \mathrm{C}\right)$ respectively.

Figure 2 shows a progressive increase in the amount of rainfall from the month of February to August after which there was a slight decrease in September and a massive decrease in October. There was no rainfall in the months of November, December and January. The highest rainfall for the period under review amount was recorded in August [206.7mm to $521 \mathrm{~mm}$ ] with September being the second highest with a total rainfall amount. Thus, Kaduna south experiences maximum rainfall peak in August/September. 


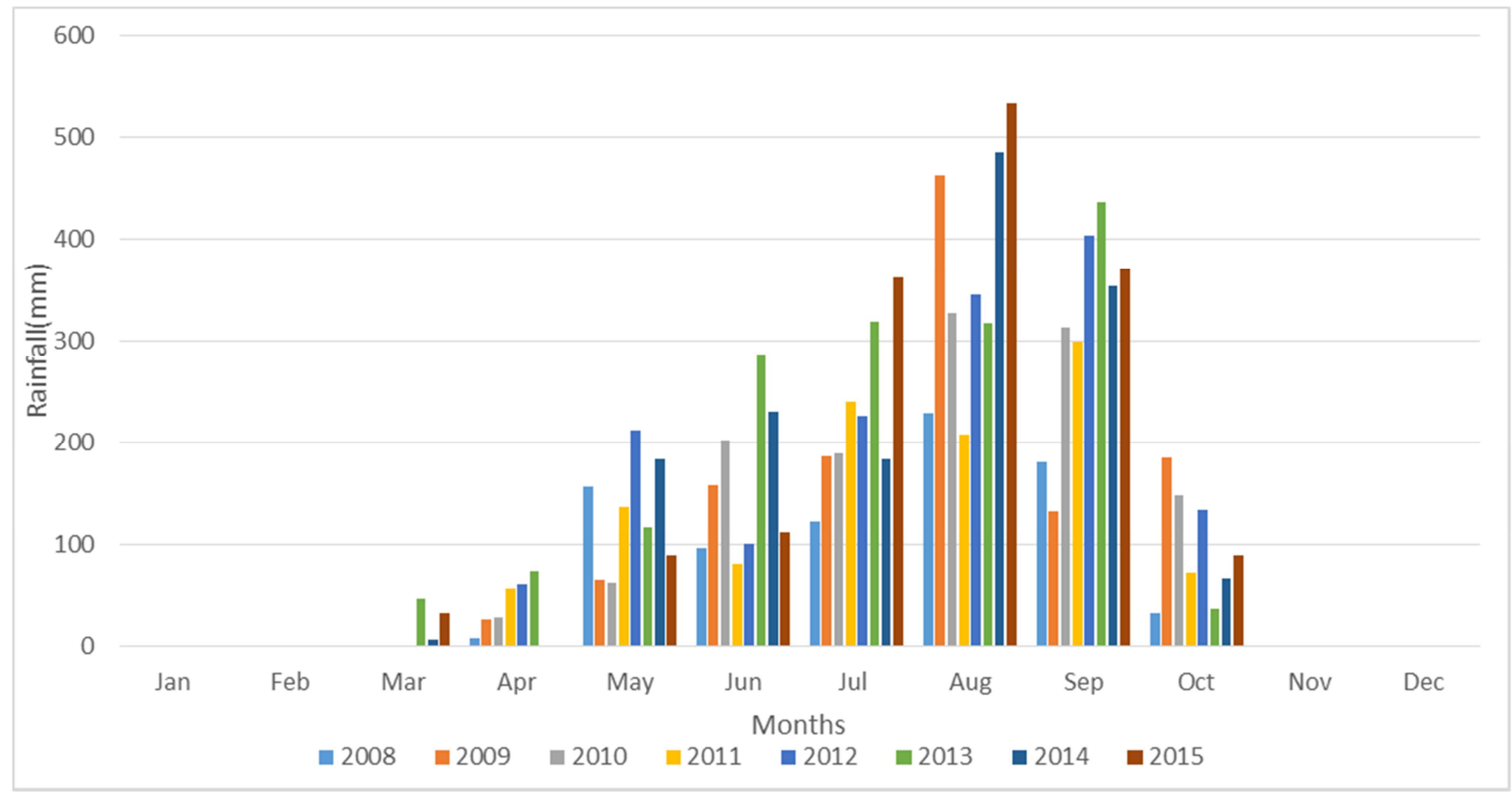

Figure 2. Rainfall Trends in Kaduna South Local Government Area.

Table 2. Relative humidity (\%) from 2008-2015, along with monthly and annual means.

\begin{tabular}{|c|c|c|c|c|c|c|c|c|c|c|}
\hline MONTH & 2008 & 2009 & 2010 & 2011 & 2012 & 2013 & 2014 & 2015 & TOTAL & MONTHLY MEAN \\
\hline JAN & 29 & 26 & 25 & 21 & 24 & 25 & 29 & 23 & 202 & 25.3 \\
\hline FEB & 18 & 18 & 23 & 29 & 22 & 32 & 29 & 26 & 197 & 24.6 \\
\hline MAR & 27 & 20 & 25 & 22 & 19 & 40 & 34 & 31 & 218 & 27.3 \\
\hline APR & 41 & 57 & 43 & 40 & 58 & 60 & 47 & 28 & 374 & 46.8 \\
\hline MAY & 68 & 67 & 70 & 73 & 70 & 71 & 71 & 62 & 552 & 69.0 \\
\hline JUN & 75 & 77 & 78 & 76 & 76 & 76 & 77 & 74 & 609 & 76.1 \\
\hline JUL & 79 & 79 & 82 & 78 & 78 & 78 & 80 & 78 & 632 & 79.0 \\
\hline SEP & 78 & 78 & 71 & 80 & 80 & 79 & 79 & 81 & 626 & 78.3 \\
\hline OCT & 65 & 78 & 77 & 73 & 75 & 65 & 71 & 74 & 578 & 72.3 \\
\hline NOV & 33 & 44 & 49 & 39 & 46 & 39 & 42 & 39 & 331 & 41.4 \\
\hline DEC & 31 & 27 & 30 & 26 & 30 & 30 & 29 & 28 & 231 & 28.9 \\
\hline TOTAL & 627 & 652 & 656 & 639 & 661 & 677 & 670 & 629 & & \\
\hline ANNUAL MEAN & 52.3 & 54.3 & 54.7 & 53.3 & 55.1 & 56.4 & 55.8 & 52.4 & & \\
\hline
\end{tabular}

With reference to table 2, Kaduna South experiences a fairly high percentage of relative humidity ranging from 69$82 \%$ in the months of May to October. While the remaining months experience low relative humidity of about $25-47 \%$.
The highest relative humidity was recorded in the month of August with $82.4 \%$ relative humidity while the lowest was recorded in February $24.6 \%$.

Table 3. Number of Pneumonia cases from 2008-2015, along with monthly and annual means.

\begin{tabular}{|c|c|c|c|c|c|c|c|c|c|c|}
\hline MONTH & 2008 & 2009 & 2010 & 2011 & 2012 & 2013 & 2014 & 2015 & TOTAL & MONTHLY MEAN \\
\hline JAN & 7 & 6 & 137 & 91 & 2 & 2 & 9 & 4 & 258 & 32.3 \\
\hline FEB & 3 & 3 & 6 & 85 & 10 & 0 & 42 & 26 & 175 & 21.8 \\
\hline MAR & 7 & 9 & 8 & 104 & 6 & 22 & 13 & 15 & 184 & 23.0 \\
\hline APR & 7 & 3 & 6 & 55 & 7 & 8 & 14 & 1 & 101 & 12.6 \\
\hline MAY & 7 & 34 & 12 & 8 & 8 & 4 & 7 & 0 & 130 & 16.3 \\
\hline JUN & 15 & 2 & 8 & 25 & 9 & 2 & 13 & 20 & 94 & 11.7 \\
\hline JUL & 9 & 12 & 9 & 25 & 5 & 8 & 2 & 14 & 84 & 10.5 \\
\hline AUG & 11 & 6 & 76 & 9 & 31 & 22 & 0 & 27 & 182 & 22.7 \\
\hline SEP & 2 & 2 & 65 & 7 & 11 & 8 & 11 & 29 & 135 & 16.8 \\
\hline OCT & 5 & 2 & 56 & 3 & 10 & 20 & 30 & 7 & 133 & 16.6 \\
\hline $\mathrm{NOV}$ & 7 & 12 & 42 & 7 & 17 & 5 & 0 & 4 & 94 & 11.7 \\
\hline DEC & 2 & 6 & 83 & 3 & 0 & 6 & 13 & 3 & 116 & 14.5 \\
\hline TOTAL & 82 & 147 & 508 & 422 & 116 & 107 & 154 & 150 & & \\
\hline ANNUAL MEAN & 6.8 & 12.3 & 42.3 & 35.2 & 9.6 & 8.9 & 12.8 & 12.5 & & \\
\hline
\end{tabular}


Table 3 indicates that the number of pneumonia cases varied from month to month. The month of January, February, March and August had high cases of pneumonia.

January, February and March are characterized by low relative humidity, suggesting that the lower the relative humidity, the higher the number of pneumonia cases. January and February are also characterized by low temperatures, suggesting that the lower the temperature the higher the number of pneumonia cases. What this means is that a combined effect of both low relative humidity and low temperature could lead to an increase in the occurrence of pneumonia.

August which is the month with the maximum rainfall amount recorded the second highest number of pneumonia cases. Rainy days are usually cold days and as such are characterized by relatively low temperature. This could also explain the reason for the high occurrence of pneumonia in the month. This also affirms that low temperatures could lead to an increase in the occurrence of pneumonia. The year 2010 recorded the highest total number of pneumonia cases. In this same year, the month of January, followed by December and August recorded the highest cases of pneumonia revealing the same pattern discussed above. This observation is also in the affirmation that low temperature and low relative humidity could lead to an increase in the occurrence of pneumonia.

\subsection{Relationship Between Pneumonia and Climatic Variables}

The ordinary least square estimates of the multiple regression model for the relationship between pneumonia and the climatic parameters for rainfall, temperature and humidity is presented in Table 4.

Table 4. Relationship between Pneumonia and Climatic Variables in Kaduna South LGA

\begin{tabular}{lllll}
\hline Variables & Coefficient & Standard Error & T-Ratio & P-value \\
\hline Constant & 5.77 & 5.19 & 1.17 & 0.34 \\
Rainfall & 0.02 & 0.31 & $4.56^{* * *}$ & 0.44 \\
Temperature & 0.05 & 0.02 & $-1.17^{* *}$ & 0.001 \\
Humidity & 0.03 & 0.01 & & 0.003 \\
Model Fitness & & & & \\
R Square & 0.16 & & & \\
F Statistic & 5.44 & & & \\
\hline
\end{tabular}

Note: $* * *$ and $* *$ Significant at 1 and $5 \%$ Level of Probability respectively.

The F-statistic was estimated to be 5.44 with a P-value of 0.0002 . The P-value being less than the standard value (0.01), the model run indicates that the combined effect of temperature, rainfall and humidity was significant at $1 \%$ levels of probability. Therefore a significant level of relation exist between Pneumonia and the climatic parameters used. It is pertinent to state that the variation in the reported cases of Pneumonia was low. That is, only $16 \%$ of variation in pneumonia was due to the climatic parameters used in this study. In other word, other climatic and human induced factors might be directly or indirectly linked to the incidence of Pneumonia in the study area.

\subsection{Seasonal Occurrence of Pneumonia}

Table 5 is a report on the seasonal occurrence of pneumonia regarded into five (Cold, Dry, Hot, Warm and Wet) combinations. In 2008 and 2009 the incidence of pneumonia is more during the warm and wet season whereas it recorded low cases in the dry /cold (for 2008) and cold/wet for 2009. In 2010, incidence of pneumonia was more in the cold and dry season with about 83 cases in December. Whereas it recorded low cases during the hot and dry season, as well as the warm and wet season.

Table 5. Seasonal Occurrence of Pneumonia.

\begin{tabular}{|c|c|c|c|c|c|c|c|c|c|c|c|c|}
\hline & \multicolumn{2}{|c|}{ Cold and dry } & \multicolumn{2}{|c|}{ Hot and dry } & \multicolumn{2}{|c|}{ Warm and Wet } & \multicolumn{2}{|c|}{ Cold and Wet } & \multirow[b]{2}{*}{ SEP } & \multirow[b]{2}{*}{ OCT } & \multicolumn{2}{|c|}{ Cold and dry } \\
\hline & JAN & FEB & MAR & APR & MAY & JUN & JUL & AUG & & & NOV & DEC \\
\hline 2008 & 7 & 3 & 7 & 7 & 7 & 15 & 9 & 11 & 2 & 5 & 7 & 2 \\
\hline 2009 & 6 & 3 & 9 & 3 & 84 & 12 & 12 & 6 & 2 & 2 & 12 & 6 \\
\hline 2010 & 6 & 3 & 9 & 3 & 84 & 12 & 12 & 6 & 2 & 2 & 12 & 6 \\
\hline 2011 & 91 & 85 & 104 & 55 & 8 & 25 & 25 & 9 & 7 & 3 & 7 & 3 \\
\hline 2012 & 2 & 10 & 6 & 7 & 8 & 9 & 5 & 31 & 11 & 10 & 17 & 0 \\
\hline 2013 & 2 & 0 & 22 & 8 & 4 & 2 & 8 & 22 & 8 & 20 & 5 & 6 \\
\hline 2015 & 4 & 26 & 15 & 1 & 0 & 20 & 14 & 27 & 29 & 7 & 4 & 3 \\
\hline
\end{tabular}

The cold and wet season also recorded high cases of pneumonia. For 2011, the cold and dry and the Hot and dry season recorded high cases of pneumonia while some months in the cold and Wet and cold month recorded low cases of pneumonia. In 2012, that the highest case of pneumonia was recorded in the cold and wet season while the hot and dry month recorded low cases of pneumonia. As reported in Table 5, in 2013, the cold and wet season recorded more pneumonia case while the warm and wet season recorded low cases. The year 2014 recorded more pneumonia cases in the 
cold and dry season. While the warm and wet season recorded low cases of pneumonia. Finally, in 2015 pneumonia cases occurred more in the cold and Wet season where as it was low in the Hot and dry season.

\section{Conclusion}

This study have established that weather elements in Kaduna South LGA play a role in the incidence of pneumonia. Therefore Climatic factors are important and should be considered along with other factors in mitigating the spread of pneumonia. The relationship between pneumonia and weather element has been established. But apart from weather, other factors such as indoor smoke, refusal to take vaccines due to ignorance, poverty and others account for the outbreak of pneumonia in the study area. There is need for the public to be enlightened about climate change, its effects and the means of mitigating or moderating its impact in order to reduce the influence of weather on pneumonia and other respiratory diseases.

\section{Acknowledgements}

The Authors will like to thank the Ministry of Health, Kaduna State and NIMET for providing datasets for this study.

\section{References}

[1] IPCC, 2014: climate change 2014: synthesis report. Contribution of Working Groups IIPCC, Geneva, Switzerland, 2014.

[2] Marcus B. (2012). The influence of weather element on the occurrence of common diseases in Kafanchan Kaduna State. Department of Geography. Ahmadu Bello University, Zaria.

[3] WHO (2003), Climate change and Human Health. Risk and Response, France.

[4] Mgwede C. W., and Msiska O., 2018, Determination of seasonal occurrence of Camallanus sp. and Ligula intestinalis on fresh Usipa, Engraulicypris sardella from selected Mzuzu markets, Malawi, International Journal of Aquaculture, 8 (5): 29-37 (doi: 10.5376/ija.2018.08.0005).

[5] Wardlaw, T. M. J., Emily white; Hodge, Mathew 2006. Pneumonia: The forgotten killer of children. Available: http://www.who.int/material.child.adolescent/documents/9280 64.0489/en/.

[6] Pharmaceutical Society of Nigeria - Partnership For Advocacy in Child and Family Health (2016) extracted online from https://www.vanguardngr.com/2016/04/20-kadunachildren-die-5th-birthday-psn-pacfah-survey/Adebayo, A. A. (2000). Temperature variability and outbreak of measles and meningitis in Yola, Nigeria. Global Journal of Applied Sciences. 7 (1), pp 133-135.

[7] Justin K. Davis, Geoffrey P. Vincent, Michael B. Hildreth, Lon Kightlinger, Christopher Carlson, Michael C. Wimberly, (2018). Improving the prediction of arbovirus outbreaks: A comparison of climate-driven models for West Nile virus in an endemic region of the United States, Acta Tropica, Volume 185, 2018, Pages 242-250, ISSN 0001-706X, https://doi.org/10.1016/j.actatropica.2018.04.028.

[8] Ojo, O, (2003). The climate of West Africa. Heinman, London, pp 63-69.

[9] Tania A. Thimraj, Leema George, Syed Asrafuzzaman, Swapna Upadhyay, Koustav Ganguly, (2018).

[10] Chapter 7 - Oxidative Signaling in Chronic Obstructive Airway Diseases, Editor (s): Shampa Chatterjee, Wolfgang Jungraithmayr, Debasis Bagchi, Immunity and Inflammation in Health and Disease, Academic Press, 2018, Pages 79-98, ISBN 9780128054178, https://doi.org/10.1016/B978-0-12805417-8.00007-X.

[11] Ali, I. A (2004). Effects of Industrial Waste Pollution of River Kaduna on Economic Lives of the People in the Southern Part of Kaduna Metropolis. (Unpublished master's thesis) Geography Department A. B. U Zaria, Nigeria.

[12] Cole, T. J. (2000), Sympercents: symmetric percentage differences on the $100 \log _{\mathrm{e}}$ scale simplify the presentation of $\log$ transformed data. Statist. Med., 19: 3109-3125. doi: 10.1002/1097-0258 (20001130) 19:22 < 3109: AID-SIM558 > 3.0. $\mathrm{CO} ; 2-\mathrm{F}$. 